\title{
COMPARAÇÃO DA EFICÁCIA DE TÉCNICAS DE NUCLEAÇÃO PARA RESTAURAÇÃO DE ÁREA DEGRADADA NO SUL DO BRASIL
}

\author{
Suzane Bevilacqua Marcuzzo ${ }^{1}$, Gislene Ganade², Maristela Machado Araújo ${ }^{3}$, \\ Marlove Fátima Brião Muniz ${ }^{4}$ \\ ${ }^{1}$ Eng $^{\mathrm{a}}$. Florestal, Dr ${ }^{\mathrm{a}}$., Secretaria Estadual do Meio Ambiente, Santa Maria, RS, Brasil - smarcuzzo@ gmail.com \\ ${ }^{2}$ Bióloga, Dra., Depto. de Botânica e Ecologia, Centro de Biociências, UFRN, Natal, RN, Brasil - gganade@gmail.com \\ ${ }^{3}$ Eng $^{\mathrm{a}}$. Florestal, Dr ${ }^{\mathrm{a}}$., Depto. de Ciências Florestais, UFSM, Santa Maria, RS, Brasil - araujo.maristela @ gmail.com \\ ${ }^{4}$ Eng $^{\mathrm{a}}$. Agrônoma, Dr ${ }^{\mathrm{a}}$., Depto. de Fitopatologia, UFSM, Santa Maria, RS, Brasil - marlovemuniz@yahoo.com.br
}

Recebido para publicação: 26/08/2012 - Aceito para publicação: 14/03/2013

\begin{abstract}
Resumo
O desenvolvimento de grandes centros urbanos em áreas naturais resultou na supressão e degradação de florestas. A fim de obter ferramentas para implantação de programas de restauração nessas áreas, este estudo teve como objetivo avaliar a eficiência de diferentes técnicas nucleadoras sobre os fatores bióticos e abióticos que limitam a regeneração natural, em uma área degradada em remanescente de floresta, no perímetro rural-urbano de Porto Alegre, RS, Brasil. O experimento foi conduzido em blocos inteiramente casualizados, em esquema fatorial, composto pelos seguintes tratamentos: Controle (C), Transposição de Solo (TS), Resíduos da Arborização Urbana Triturados (RT), Transposição de Solo misturado aos Resíduos da Arborização Urbana Triturado (TS+RT) e Poleiros Artificiais. Durante 12 meses, foi avaliada a abundância e riqueza de plântulas estabelecidas, e por sete meses, a chuva de sementes em coletores. Os resultados indicam que a transposição de solo foi o método mais eficiente para restauração da área degradada em estudo. Adicionalmente, a utilização de poleiros artificiais se mostrou eficiente, indicando tendência de aumento da riqueza florística e de sementes dispersas. No entanto, a vegetação exótica da área urbana apresentou forte influência na composição florística, cuja sucessão terá trajetória diferente da vegetação original.

Palavras-chave: Nucleação; poleiros artificiais; arborização urbana; transposição de solo.
\end{abstract}

\begin{abstract}
Comparison of nucleation techniques effectiveness for degraded area restoring in Southern Brazil. The development of large urban centers in natural areas resulted in abolition and degradation of forests. In order to obtain tools for restoring programs development in such areas, this study aimed to evaluate efficiency of different nucleus techniques in relation to biotic and abiotic factors which limit natural regeneration in a depressed area of remnant forest in rural-urban perimeter of Porto Alegre, RS, Brazil. The experiment was conducted in randomized blocks, in factorial disposition, composed of the following treatments: Control (C), Transposition of Soil (TS), crushed waste of urban afforestation (RT), Transposition of soil mixed to crushed waste of urban afforestation (TS+RT), and artificial perches. During 12 months, abundance and richness of seedlings laid down were evaluated and for seven months the seed rain in sinks. Results point that the soil transposition was the most efficient method for restoration of the degraded area. Additionally, artificial perches using proved to be efficient, pointing to wealth increase trend and floristic wealth of dispersed seeds. However, the exotic vegetation of the urban area has strong influences on floristic composition, whose succession will have different trajectory of original vegetation.
\end{abstract}

Keywords: Artificial perches; nucleation; urban afforestation; soil transposition.

\section{INTRODUÇÃO}

O desenvolvimento dos grandes centros urbanos resultou na supressão e degradação das áreas florestais, podendo-se citar, como exemplo, a redução da Mata Atlântica, que antes ocupava grande parte da costa litorânea brasileira, restando, atualmente, de sua área original, apenas fragmentos de floresta (FOOD AND AGRICULTURE ORGANIZATION (FAO), 2004). A composição florística e estrutural desse bioma 
foi modificada em decorrência da fragmentação, muitas vezes comprometendo sua estabilidade, diminuindo sua resiliência e a resistência a distúrbios (LAURENCE; VASCONCELOS, 2009).

Voss (1985) aponta que os fragmentos florestais urbanos são áreas resultantes do avanço da urbanização sobre os ecossistemas naturais. Algumas regiões metropolitanas, que apresentam arborização urbana expressiva, entremeada com remanescentes de vegetação, percebem a importância da restauração dessas áreas e do planejamento da arborização, na forma de corredores de biodiversidade, permitindo que ocorra a ligação entre esses fragmentos e a interação fauna-flora.

A restauração busca o retorno da estabilidade e integridade biológica dos ecossistemas naturais, a fim de permitir a presença de espécies características da área. Além disso, permite assistir e direcionar os processos naturais para características desejáveis no sistema futuro (YOUNG, 2000; LAMB; GILMOUR, 2003).

Porém diversos trabalhos demonstraram que vários fatores bióticos (baixas taxas de chuva de sementes, ausência de dispersores, predação de sementes) e abióticos (compactação do solo, erosão, alteração de temperatura) limitam a regeneração florestal (AIDE; CAVALIER, 1994; CALLAWAY; WALKER, 1997; MELO et al., 2000). Nesse contexto, a nucleação propicia que determinadas espécies melhorem as condições ambientais de um ecossistema degradado, permitindo sua ocupação por outras espécies mais exigentes na escala sucessional (YARRANTON; MORRISON, 1974).

Assim, a fim de atrair a diversidade e funcionalidade local para a área degradada, algumas técnicas de nucleação foram aplicadas buscando atender esses objetivos, entre as quais, a transposição de banco de sementes (GARWOOD, 1989; VAZQUEZ-YANES; OROZCO-SEGOVIA, 1993; MARTINS, 2008), transplante de plântulas (DESLOW, 1991; VIANI et al., 2007), plantio em grupos (ANDERSON, 1953) e uso de poleiros artificiais para atração de aves (MELO et al., 2000) e morcegos, que pousam e defecam nesses locais, depositando sementes de fragmentos de florestas próximas.

A transposição de solo possibilita a reestruturação e fertilização do solo pela presença microbiológica no banco de solo, responsável pela ciclagem de nutrientes, além da composição de sementes, que, ao germinarem, proporcionam a revegetação da área degradada. Adicionalmente, a transposição de galharia é formada por restos vegetais, como galhos, folhas e material reprodutivo, da floresta, áreas de produção ou arborização urbana, que oferecem abrigo para pequenos animais (REIS; TRES, 2007).

Nesse contexto, este trabalho teve por objetivo identificar, entre os diferentes métodos de restauração aqui utilizados, o método de maior potencial para o estabelecimento da regeneração natural na área degradada em remanescente de floresta próximo de área urbana.

\section{MATERIAL E MÉTODOS}

\section{Área de estudo}

O trabalho foi realizado em um remanescente de floresta secundária em encosta de um morro granítico, o qual é parte de um loteamento urbano no município de Porto Alegre (30³5' $\mathrm{S}, 48^{\circ} 07^{\prime} \mathrm{W}$ ), RS, Brasil (Figura 1). A área apresenta uma altitude máxima de 147 m, e o clima, segundo a classificação de Köppen, é denominado subtropical, com temperatura média anual de $19{ }^{\circ} \mathrm{C}$, com precipitação média anual de $1300 \mathrm{~mm}$ (NIMER, 1990).

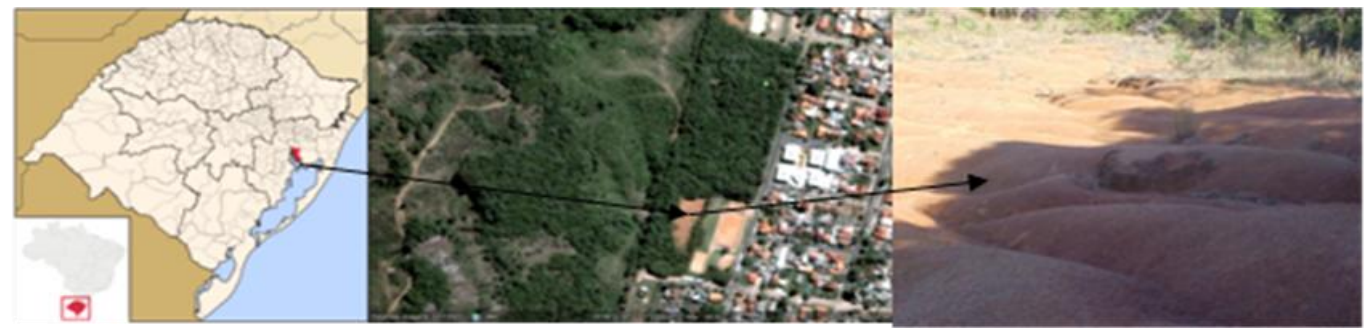

Fonte: Google Earth (2003)

Figura 1. Localização de área submetida aos diferentes métodos de restauração no município de Porto Alegre, RS, Brasil.

Figure 1. Location of the area subjected to different methods of restoration in the municipality of Porto Alegre, RS, Brazil. 
A área de estudo faz parte da crista de morros graníticos, resultante do afloramento ou desagregação autóctone do Escudo Sul-Brasileiro, vinculado à Serra do Sudeste (KNOB, 1978). A vegetação característica da região denomina-se "Área de Tensão Ecológica”, conforme Veloso e GóesFilho (1982), com espécies representantes de Floresta Estacional Decidual, Floresta Ombrófila Densa, formação de Savana e Restinga. Atualmente, a vegetação natural remanescente na região é constituída por um mosaico de diferentes estágios sucessionais, resultantes dos diversos processos de uso antrópico, além da adjacência com área urbana, arborizada com espécies arbóreas nativas e exóticas.

O histórico de uso da área refere-se à movimentação de solo para obras do loteamento urbano, dando início a um processo erosivo, com perda das primeiras camadas de solo. A área utilizada nesse estudo é constituída por $2520 \mathrm{~m}^{2}$ de solo erodido sem nenhuma forma de vida vegetal, localizada na borda de um fragmento de floresta secundária alterada.

\section{Desenho experimental}

O experimento foi instalado em abril de 2004, em seis blocos ao acaso, com arranjo fatorial $4 \times 2$, acompanhando a declividade do terreno, cada bloco com quatro parcelas de $5,0 \times 5,0 \mathrm{~m}$, que receberam, além da testemunha (controle), três coberturas do solo: a) Transposição de solo (TS), na qual o solo utilizado para cobertura foi retirado do fragmento de floresta adjacente, $c 0 m 10 \mathrm{~cm}$ de espessura de solo com serapilheira dispostos por parcela; b) Resíduos da arborização urbana triturado (RT), resultante da poda de árvores urbanas (galhos com folhas, frutos e sementes), processados em um triturador de resíduos arbóreos marca TRAPP ${ }^{\circledR}$ TR 500, cujo material foi reduzido a fragmentos com a espessura menor que $5 \mathrm{~cm}$ e dispostos $5 \mathrm{~cm}$ como cobertura nas parcelas desse tratamento; c) transposição de solo adicionado aos resíduos da arborização urbana triturado (TS+RT), cada um com a presença ou ausência de poleiros artificiais. A transposição de solo e do resíduo da arborização sofreu um leve arraste após a primeira chuva, devido à declividade do terreno, se depositando nas ravinas fora das parcelas (Figura 2), mas posteriormente se manteve o suficiente nas parcelas, não comprometendo o experimento.
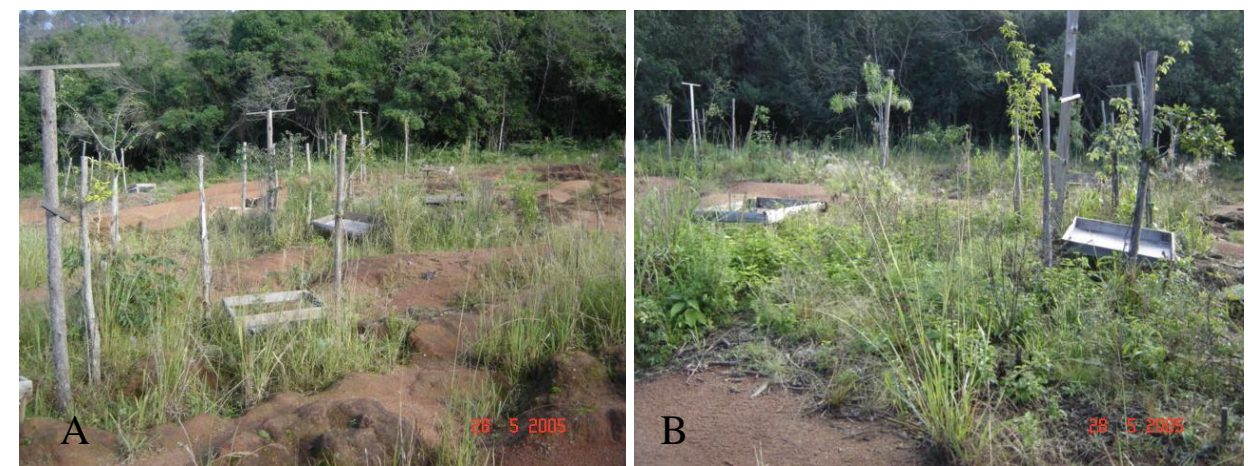

Figura 2. Área do experimento após 12 meses de implantação: (A) ravinas entre as parcelas; (B) parcela com vegetação estabelecida no tratamento (TS+RT).

Figure 2. Area of the experiment after 12 months of implementation: (A) gullies between the plots; (B) installment with established vegetation in treatment (TS+RT).

Em cada parcela, foram demarcadas duas subparcelas de $1 \mathrm{~m}^{2}$, em lados opostos e diagonais, sendo que uma dessas recebeu, de forma aleatória, um poleiro. Os poleiros foram constituídos de ripas de madeira de $3 \mathrm{~m}$ de altura e com $10 \times 10 \mathrm{~cm}$ de largura, tendo transversalmente, na ponta superior, uma ripa de $2 \mathrm{~m}$ de comprimento e 2,0 x 2,0 cm de largura.

Dentro das subparcelas, foram instalados dois coletores de sementes confeccionados em madeira, distantes um metro da parcela com poleiro e três metros da parcela sem poleiro, com as dimensões de 1,0 x 1,0 m, com fundo de ráfia e disposto sobre pés de $10 \mathrm{~cm}$ de altura, para determinação da dispersão de sementes por aves, na presença e ausência de poleiros, totalizando 48 coletores na área. Os coletores de chuva de sementes localizavam-se distantes do fragmento florestal vizinho aproximadamente de $10 \mathrm{a}$ 40 metros. 


\section{Coleta de dados}

Medições de estabelecimento de plântulas

Durante 12 meses, entre abril de 2004 e março de 2005, foi observado o número de plântulas de espécies arbóreas em todas subparcelas. Para cada mês, foi utilizado um fio de acrílico de cor diferente, marcando as plântulas estabelecidas a partir do surgimento das primeiras folhas verdadeiras, as quais foram identificadas, de forma a evitar a recontagem no mês seguinte.

No final do estudo, última coleta de dados, foram verificadas a abundância, riqueza de plântulas que se encontravam na subparcela de um $\mathrm{m}^{2}$ (valor acumulado), mortalidade de indivíduos de espécies arbóreas e o percentual de cobertura de vegetação na parcela de $25 \mathrm{~m}^{2}$, conforme escala combinada de abundância-cobertura proposta por Braun-Blanquet (1979), em que há uma divisão em categorias de cobertura, onde a escala 6 é igual a cobertura vegetal maior que $3 / 4$ da área, 5 é igual a cobertura vegetal variando de $1 / 2$ a 3/4 da área, 4 é definida pela cobertura de $1 / 4$ a 1/2 da área, 3 é de $1 / 10$ a 1/4 da área, 2 cobre $1 / 10$ da área e 1 é designado para área que apresenta menos de 5\%, mesmo que ainda com indivíduos isolados.

Observações da chuva de sementes

A riqueza e a abundância das sementes observadas nos coletores foram monitoradas por sete meses, a partir de julho de 2004 até janeiro de 2005. O material coletado foi depositado em sacos de papel, sendo separado e identificado em laboratório com auxílio de microscópio estereoscópio. Em seguida, as sementes foram separadas dos frutos. Os diásporos encontrados foram registrados e sua identificação foi feita por comparações com material fértil coletado de espécies arbóreas na área de estudo, material da espermateca da Fundação ZooBotânica (FZB) e por consulta a bibliografia específica (BACKES; IRGANG, 2002).

\section{Análise dos dados}

Para investigar a eficiência dos tratamentos com e sem poleiros na dispersão das sementes e no ingresso de plântulas, durante os 12 meses do experimento, ou seja, referente ao período total de estudo, foi realizada uma análise de variância de medidas repetidas no tempo mensalmente. A mesma análise foi utilizada para a observação de dispersão de sementes nos coletores durante sete meses, época de maior frutificação da formação florestal característica da região. Para abundância, riqueza de plântulas estabelecidas e percentual de cobertura de herbáceas no final do período de coleta de dados, foi empregada uma análise de variância. Para tais análises, foram utilizados os procedimentos de modelagem linear do programa estatístico SYSTAT 10 (2000, SSPS Inc., Chicago, IL, EUA).

A composição florística de plântulas estabelecidas nos diferentes tratamentos foi comparada por meio do teste de Tukey realizado com o auxílio do software Statistical Analysis System (SAS) 8.2 (SAS, 1999).

\section{RESULTADOS E DISCUSSÃO}

Durante os doze meses, foram observadas 1.969 plântulas em todos os tratamentos ao longo do tempo na área, porém, no final do período do experimento, restaram apenas $21,6 \%$ desse total registrado, ocorrendo uma mortalidade em torno de $78 \%$ de plântulas. A abundância de plântulas foi maior nos tratamentos contendo resíduo triturado $\left(F_{[1,30]}=9.984 ; p<0.01\right.$, Figura 3), não havendo interação com o fator poleiros. A elevada abundância de plântulas com tratamento RT, provavelmente, ocorreu devido ao grande número de frutos e sementes misturados aos galhos triturados, de espécies nativas e exóticas da arborização urbana. Tal situação incrementou o ingresso de propágulos de espécies arbóreas na parcela, com pico no mês de setembro, quando, após o inverno, as condições ambientais favoreceram a germinação.

Cabe ressaltar que, conforme o Plano Diretor de Arborização Urbana de Porto Alegre, 71,73\% da arborização urbana são compostos por árvores exóticas e $28,27 \%$ de árvores nativas regionais. Dessa forma, a tendência é que sejam dispersas em maior quantidade as sementes de espécies exóticas na região.

Adicionalmente, a principal influência positiva ocasionada pelo tratamento RT se deve à barreira ao processo erosivo, estabelecidas pelos fragmentos de galhos, os quais reduziram o escoamento 
superficial da água da chuva, proporcionando redução da retirada de matéria orgânica e ocasionando seu acúmulo, conforme já observado por Suzuki e Alves (2005) em área com processo erosivo.

Entretanto, esse mesmo tratamento apresentou a maior mortalidade $\left(F_{[1,30]}=12.989 ; p<0.001\right.$, Figura $4 \mathrm{C}$ ). Acredita-se que esse fato ocorreu pela exposição das plântulas à alta radiação solar do período de verão, pois nesse tratamento não se desenvolveu uma cobertura de plantas herbáceas ou ruderais, em virtude de o banco de sementes desse tratamento ser de espécies arbóreas. As plantas herbáceas encontradas no banco de sementes, ao germinarem, crescem rapidamente, sombreando o solo. Conforme Callaway (1995), plântulas de espécies lenhosas são beneficiadas pela cobertura de herbáceas no ambiente, protegendo o solo e as plântulas das altas radiações e temperaturas.

Ainda, referente à abundância de plântulas, o tratamento de transposição de solo (TS) sem poleiro $\left(F_{[1,30]}=7.026 ; p<0.05\right.$, Figura 3$)$ apresentou diferença significativa em relação à abundância de plântulas, devido, provavelmente, ao mesmo fator relacionado ao tratamento de RT, a germinação de plântulas do banco de sementes. A transposição de solo permite resgatar populações de diversas espécies da microbiologia do solo, responsáveis pela ciclagem de nutrientes e, por apresentar espécies pioneiras herbáceas e arbustivo-arbóreas de ciclo de vida curto, possibilitam a formação de um microclima propício para o estabelecimento de novos indivíduos (BAIDER et al., 1999).

Também ocorreu diferença significativa com o tratamento TS+RT em interação com poleiro $\left(F_{[1,30]}=4.458 ; p<0.05\right.$, Figura 3 e $\left.4 \mathrm{~B}\right)$, com o uso do poleiro pela avifauna incrementando a dispersão de sementes no mês de setembro, período da primavera, em que ocorre intensa frutificação em florestas da região (MORELLATO, 1995). As sementes dispersadas encontraram nesse tratamento boas condições para germinar, devido ao aporte de matéria orgânica, resultando em um número significativo de plântulas. Ainda, esse tratamento apresentou a maior riqueza de plântulas $\left(F_{[1,30]}=43.73 ; p<0.001\right.$, Figura $\left.4 \mathrm{~A}\right)$, em virtude de ter combinado a diversidade do banco de sementes dos resíduos triturados e do solo da floresta com as espécies dispersas pela fauna.

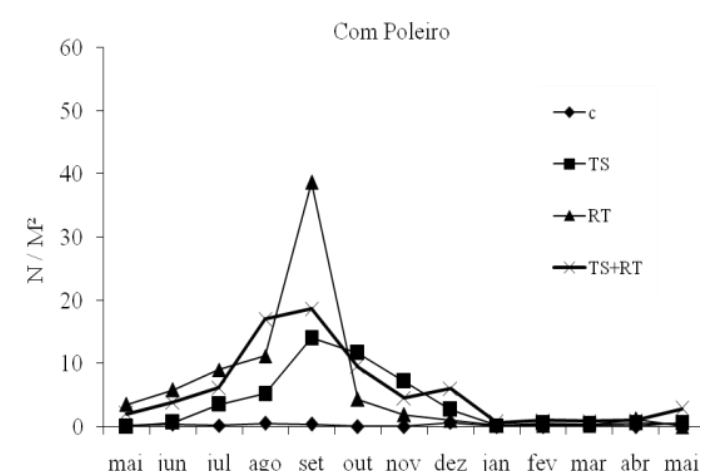

mai jun jul ago set out nov dez jan fev mar abr mai

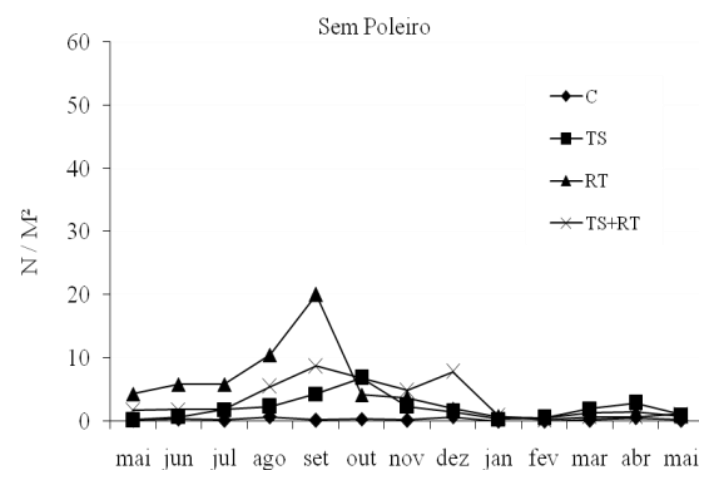

Figura 3. Abundância de plântulas $\left(\mathrm{N} / \mathrm{m}^{2}\right)$ observadas durante 12 meses de monitoramento em diferentes coberturas de solo, com e sem poleiro, Porto Alegre, RS, Brasil.

Figure 3. Seedling abundance $\left(\mathrm{N} / \mathrm{m}^{2}\right)$ observed during 12 months of monitoring in different soil covers, with perch and without perch, Porto Alegre, RS, Brazil.

O tratamento TS oportunizou nas parcelas o desenvolvimento de herbáceas das famílias Asteraceae, Bignoniaceae, Convolvulaceae e Solanaceae, com o que observou-se uma riqueza significativa de plântulas $\left(F_{[1,30]}=37.52 ; p<0.001\right.$, Figura 4 A) e cobertura de herbáceas $\left(F_{[1,10]}=31.154\right.$; $p<0.001$, Figura 4 D). Algumas espécies de Solanaceae produzem intensa frutificação o ano todo, sendo que esses frutos são atrativos para aves e principalmente morcegos, que são eficientes dispersores de sementes (PAISE; VIEIRA, 2005).

Essas famílias exerceram o papel de facilitadoras (GÓMEZ-APARICIO et al., 2004), por florescerem e frutificarem intensamente a partir do terceiro mês de implantação do experimento, atraindo uma biodiversidade de polinizadores e de dispersores de sementes para a área em restauração, o que, no presente trabalho, resultou em uma maior riqueza de espécies lenhosas estabelecidas. 

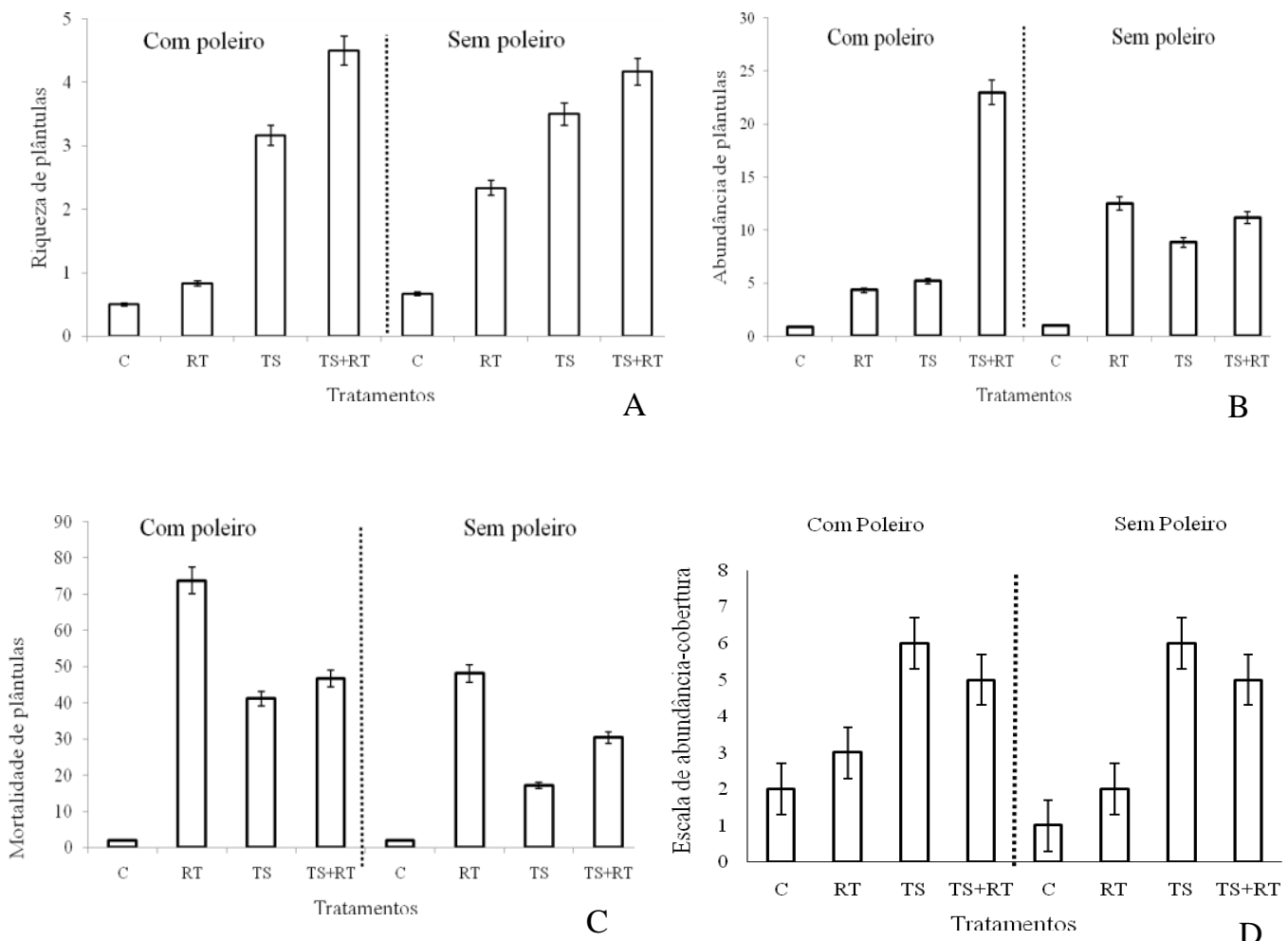

Figura 4. (A) Riqueza $\left(\mathrm{n}^{\circ} \mathrm{sp} / \mathrm{m}^{2}\right)$; (B) abundância $\left(\mathrm{n}^{\circ} \mathrm{ind} / \mathrm{m}^{2}\right)$; (C) mortalidade $\left(\mathrm{n}^{\circ} \mathrm{ind} / \mathrm{m}^{2}\right)$ de plântulas $( \pm 1$ erro padrão na linha vertical); (D) cobertura de herbáceas em $25 \mathrm{~m}^{2}$, na presença e ausência de poleiro, Porto Alegre, RS, Brasil.

Figure 4. (A) Richness $\left(\mathrm{n}^{\circ} \mathrm{sp} / \mathrm{m}^{2}\right)$; (B) abundance $\left(\mathrm{n}^{\circ} \mathrm{ind} / \mathrm{m}^{2}\right)$; (C) mortality $\left(\mathrm{n}^{\circ} \mathrm{ind} / \mathrm{m}^{2}\right)$ of seedlings $( \pm 1$ standard error on the vertical line); (D) herbaceous coverage in $25 \mathrm{~m}^{2}$, in perch presence and absence, Porto Alegre, RS, Brazil.

Ainda, pode-se observar que os resultados com e sem poleiro para abundância e mortalidade de plântulas são muito diferentes, devido à alta predação pela avifauna local predominante, que é onívora (MARCUZZO et al., 2009) e que utiliza os poleiros, aumentando a mortalidade de plântulas no local. Na Costa Rica, Shiels e Walker (2003) verificaram que, embora os poleiros incrementassem a chegada de sementes, eles não influenciavam o estabelecimento de plântulas em áreas de pastagem abandonada.

Adicionalmente, nos coletores foi encontrado um total de 10.609 sementes, sendo 6.250 nas parcelas com poleiros e 4.359 nas parcelas sem poleiro, o que representou diferença significativa em relação à abundância $\left(F_{[1,30]}=4.276 ; p<0.05\right)$ e riqueza de sementes $\left(F_{[1,30]}=9.708 ; p<0.01\right)$ para o tratamento RT (Figura 5), o qual, devido ao seu abundante banco de sementes, atrativo à avifauna, utilizou o poleiro para forragear, promovendo a dispersão de sementes de outros locais.

Além disso, diante da presença de poleiros, houve diferença significativa para riqueza de sementes $\left(F_{[1,30]}=2.635 ; p<0.05\right)$ para o tratamento TS+RT, não havendo interação significativa para os demais tratamentos. Nesse sentido, os poleiros demonstram seu papel de conectividade da paisagem, atuando como trampolins ecológicos (TRES e REIS, 2009), em que a avifauna dispersa propágulos do próprio fragmento de floresta onde a área de estudo está inserida e, provavelmente, de outros fragmentos localizados a 400 e 700 metros da mesma (AGUIAR et al., 1986). Esses resultados corroboram o estudo de Shiels e Walker (2003) em Florestas Subtropicais de Porto Rico, onde os autores encontraram um aumento significativo de riqueza de sementes zoocóricas sob poleiros artificiais.

Em torno de 42 espécies de pássaros foram observadas na região por Marcuzzo et al. (2009), os quais são potenciais dispersores de sementes. As famílias registradas no estudo eram compostas por aves na maioria generalistas, insetívoras e granívoras. Apesar disso, o uso do poleiro não influenciou a 
abundância das sementes dispersas nos coletores. De acordo com Miriti (1998), a importância de poleiros aumenta com a distância da floresta, e McDonnel e Stiles (1983) descreveram que o recrutamento de sementes também aumenta com a sua complexidade estrutural, fazendo com que árvores próximas sejam mais atrativas do que poleiros artificiais, devido ao número e arquitetura de galhos na copa. Provavelmente, a grande proximidade dos poleiros com a borda da floresta neste estudo, em torno de dez metros de distância, foi o que ocasionou esse resultado na área de estudo.
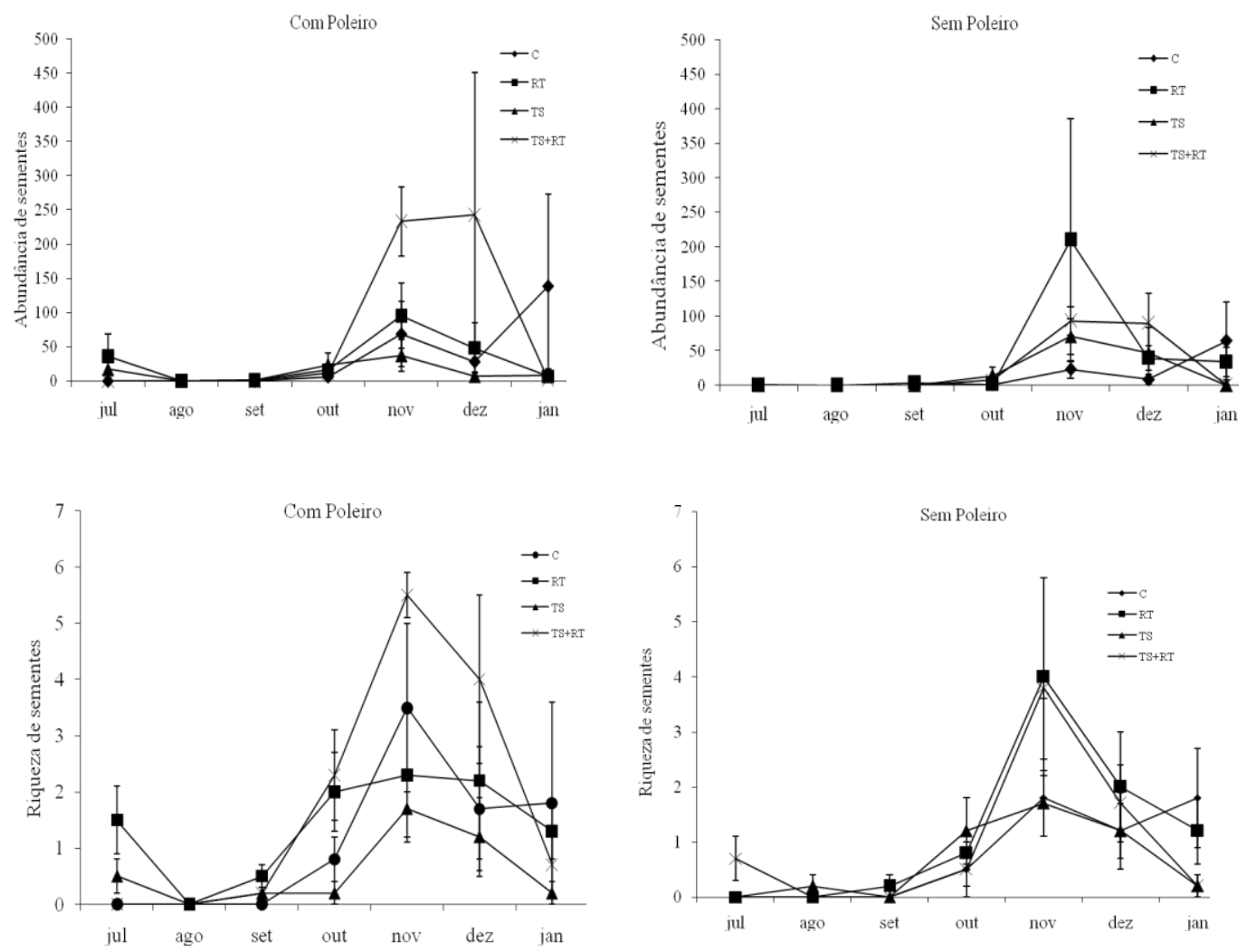

Figura 5. Abundância e riqueza médias de sementes na presença e ausência de poleiro, Porto Alegre, RS, Brasil.

Figure 5. Average richness and abundance of seeds in perch presence and absence, Porto Alegre, RS, Brazil.

$\mathrm{Na}$ composição florística nas subparcelas, foram observadas 15 espécies, pertencentes a 15 gêneros e 12 famílias. Nos tratamentos com poleiro, ocorreu o ingresso de cinco espécies exóticas e dez nativas, com a abundância de espécies exóticas sendo maior nas parcelas com poleiro, principalmente no tratamento RT (Tabela 1). Isso indica uma tendência de que as aves presentes na região são potenciais dispersoras de sementes de espécies nativas e exóticas. Esse fato pode resultar em uma modificação na composição florística de fragmentos florestais adjacentes à área urbana e das áreas em processo de regeneração natural, o que torna não recomendável o uso de poleiros para recuperar áreas degradadas nessas situações.

Nas parcelas sem poleiro, ingressaram quatro espécies exóticas e sete nativas, enquanto que nas parcelas com poleiro ocorreram cinco espécies exóticas e dez nativas, ou seja, houve maior riqueza de espécies nativas em ambas as situações (Tabela 1). Nesse contexto, destaca-se a importância do banco de sementes do solo, como se observou no tratamento TS+RT na ausência de poleiro, onde a espécie Trema micrantha apresentou elevada abundância de plântulas. Por outro lado, verificou-se o quanto a composição das espécies que compõem o tratamento de resíduos triturados pode comprometer a área a ser 
restaurada, pois, tanto na presença quanto na ausência de poleiros, ocorreu elevada abundância de plântulas de espécies exóticas, como Melia azedarach e Psidium guajava, ambas consideradas invasoras (VIEIRA; GANDOLFI, 2006).

Tabela 1. Composição florística de plântulas lenhosas estabelecidas nas parcelas $(1$ x $1 \mathrm{~m})$ com e sem poleiro.

Table 1. Floristic composition of woody seedlings established in plots $(1 \times 1 \mathrm{~m})$ with and without perch.

\begin{tabular}{|c|c|c|c|c|c|c|c|c|c|}
\hline \multirow{2}{*}{ Espécies } & \multirow{2}{*}{ Família } & \multicolumn{4}{|c|}{ Poleiro } & \multicolumn{4}{|c|}{ Sem poleiro } \\
\hline & & TS & RT & TS+RT & $\mathbf{C}$ & TS & RT & TS+RT & $\mathbf{C}$ \\
\hline \multicolumn{10}{|l|}{ Exóticas } \\
\hline Melia azedarach $\mathrm{L}$. & Meliaceae & $0 \mathrm{~d}$ & $64 \mathrm{a}$ & $5 \mathrm{c}$ & $0 \mathrm{~d}$ & $0 \mathrm{~d}$ & $17 \mathrm{~b}$ & $5 \mathrm{c}$ & $0 \mathrm{~d}$ \\
\hline Ligustrum lucidum Thumb. & Oleaceae & $2 \mathrm{~b}$ & $3 \mathrm{~b}$ & $22 \mathrm{a}$ & $0 \mathrm{c}$ & $0 \mathrm{c}$ & $1 \mathrm{c}$ & $0 \mathrm{c}$ & $0 \mathrm{c}$ \\
\hline Morus nigra $\mathrm{L}$. & Rosaceae & $12 \mathrm{a}$ & $0 \mathrm{~b}$ & $13 \mathrm{a}$ & $0 \mathrm{~b}$ & $0 \mathrm{~b}$ & $0 \mathrm{~b}$ & $0 \mathrm{~b}$ & $0 \mathrm{~b}$ \\
\hline Jacaranda mimosifolia D. Don & Bignoniaceae & $0 \mathrm{a}$ & $1 \mathrm{a}$ & $0 \mathrm{a}$ & $0 \mathrm{a}$ & $1 \mathrm{a}$ & $0 \mathrm{a}$ & $0 \mathrm{a}$ & $0 \mathrm{a}$ \\
\hline Psidium guajava $\mathrm{L}$. & Myrtaceae & $0 \mathrm{~d}$ & $17 \mathrm{~b}$ & $27 \mathrm{a}$ & $0 \mathrm{~d}$ & $0 \mathrm{~d}$ & $0 \mathrm{~d}$ & $6 c$ & $0 \mathrm{~d}$ \\
\hline Dodonea viscosa (Linn.) Jacq. & Sapindaceae & $0 \mathrm{~d}$ & $1 \mathrm{c}$ & $5 \mathrm{~b}$ & $0 \mathrm{~d}$ & $2 \mathrm{c}$ & $2 \mathrm{c}$ & $12 \mathrm{a}$ & $4 \mathrm{~b}$ \\
\hline \multicolumn{10}{|l|}{ Nativas } \\
\hline Trema micrantha (Linn.) Blume & Ulmaceae & $2 \mathrm{c}$ & $1 \mathrm{c}$ & $8 \mathrm{~b}$ & $0 \mathrm{~d}$ & $0 \mathrm{~d}$ & $0 \mathrm{~d}$ & $37 \mathrm{a}$ & $0 \mathrm{~d}$ \\
\hline Baccharis sp. & Asteraceae & $9 \mathrm{c}$ & $3 d$ & $4 \mathrm{~d}$ & $4 \mathrm{~d}$ & $10 \mathrm{~b}$ & $0 \mathrm{e}$ & $20 \mathrm{a}$ & $0 \mathrm{e}$ \\
\hline Solanum pseudoquina St.-Hil. & Solanaceae & $4 \mathrm{a}$ & $1 \mathrm{~b}$ & $0 \mathrm{~b}$ & $0 \mathrm{~b}$ & $1 \mathrm{~b}$ & $1 \mathrm{~b}$ & $0 \mathrm{~b}$ & $0 \mathrm{~b}$ \\
\hline Mimosa bimucronatha Kuntze. & Mimosaceae & $24 \mathrm{a}$ & $0 \mathrm{~d}$ & $17 \mathrm{~b}$ & $2 \mathrm{c}$ & $16 \mathrm{~b}$ & $0 \mathrm{~d}$ & $12 \mathrm{~b}$ & $2 \mathrm{c}$ \\
\hline $\begin{array}{l}\text { Allophyllus edulis (A. St.-Hil., } \\
\text { Cambess. \& A. Juss) }\end{array}$ & Sapindaceae & $0 \mathrm{~b}$ & $2 \mathrm{a}$ & $0 \mathrm{~b}$ & $0 \mathrm{~b}$ & $1 \mathrm{~b}$ & $0 \mathrm{~b}$ & $0 \mathrm{~b}$ & $0 \mathrm{~b}$ \\
\hline $\begin{array}{l}\text { Enterolobium contortisiliquum } \\
\text { (Vell.) Morong. }\end{array}$ & Mimosaceae & $0 \mathrm{a}$ & $1 \mathrm{a}$ & $0 \mathrm{a}$ & $0 \mathrm{a}$ & $0 \mathrm{a}$ & $0 \mathrm{a}$ & $0 \mathrm{a}$ & $0 \mathrm{a}$ \\
\hline Zanthoxylum roifolium Lam. & Rutaceae & $1 \mathrm{a}$ & $0 \mathrm{a}$ & $0 \mathrm{a}$ & $0 \mathrm{a}$ & $0 \mathrm{a}$ & $0 \mathrm{a}$ & $0 \mathrm{a}$ & $0 \mathrm{a}$ \\
\hline Lithraea brasiliensis March. & Anacardiaceae & $2 \mathrm{a}$ & $0 \mathrm{~b}$ & $3 a$ & $0 \mathrm{~b}$ & $0 \mathrm{~b}$ & $0 \mathrm{~b}$ & $4 \mathrm{a}$ & $0 \mathrm{~b}$ \\
\hline Celtis iguanea (Jacq.) Sargent. & Ulmaceae & $1 \mathrm{a}$ & $0 \mathrm{a}$ & $0 \mathrm{a}$ & $0 \mathrm{a}$ & $0 \mathrm{a}$ & $0 \mathrm{a}$ & $0 \mathrm{a}$ & $0 \mathrm{a}$ \\
\hline
\end{tabular}

Nota: aplicação do teste de Tukey, em que as médias com a mesma letra não apresentam diferença significativa.

Assim, os resultados revelam que todos os tratamentos se diferenciaram da testemunha em relação à abundância de plântulas, indicando que os fatores que impediam a regeneração natural na área eram de origem abiótica, relacionados à erosão, inexistência das camadas férteis do solo e declividade do terreno, impossibilitando o desenvolvimento das sementes dispersas na área. Revelam também que os tratamentos de TS+RT e TS se diferenciaram da testemunha para riqueza de plântulas, RT se diferenciou da testemunha para abundância de sementes e RT e TS+RT para riqueza de sementes.

Além disso, apesar de menor proporção, constatou-se a presença de fatores bióticos, como a dispersão de espécies exóticas e a predação de sementes e plântulas pela avifauna granívora, que influenciaram o estabelecimento de plântulas.

Os poleiros artificiais diferiram estatisticamente com relação à sua ausência e, somados aos tratamentos de transposição de solo e resíduo de poda, agiram como ferramentas nucleadoras eficientes para promover a restauração de áreas degradadas. Entretanto, nesse caso, alguns fatores, como o pequeno tamanho e isolamento dos fragmentos e o grande número de espécies exóticas presentes na arborização urbana que circunda essas áreas, influenciam negativamente o progresso da restauração, comprometendo, em curto prazo, a composição florística, sua dinâmica e expansão.

Diante dos resultados obtidos no presente trabalho, são necessárias algumas medidas de manejo para que a situação possa ser revertida, como: 1) a introdução de espécies de estádio mais avançado de sucessão; 2) substituição das espécies exóticas presentes na arborização urbana por espécies nativas, formando, assim, corredores que servirão de conectores entre os fragmentos, possibilitando o fluxo gênico entre populações de plantas; 3) utilização de técnicas de cobertura de solo para áreas em regeneração, apesar do processo erosivo, proporcionando o estabelecimento de espécies lenhosas nativas em um menor espaço de tempo e com baixo custo. Tais medidas podem fomentar e auxiliar a manutenção da biodiversidade local. 


\section{CONCLUSÃO}

- O método de nucleação que utiliza a transposição de solo adicionado aos resíduos de galhos triturados e a presença de seu banco de sementes no solo transportado facilita o processo de regeneração.

- A utilização de poleiros artificiais incrementa a entrada de sementes.

\section{REFERÊNCIAS}

AGUIAR, L. W.; MARTAU, L.; SOARES, Z. F. Estudo preliminar da flora e vegetação de morros graníticos da região da Grande Porto Alegre, Rio Grande do Sul, Brasil. Iheringia, Ser. Bot, Porto Alegre, v. 34, p. 3 - 38, 1986.

AIDE, T. M.; CAVALIER, J. Barriers to tropical lowland forest restoration in the Sierra Nevada de Santa Marta, Colômbia. Restoration Ecology, v. 2, p. 219 - 229, 1994.

ANDERSON, M. L. Spaced-group planting. Unasylva, v. 7, n. 2, p. 12 - 18, 1953.

BACKES, P.; IRGANG, B. Árvores do Sul: guia de identificação e interesse ecológico. Santa Cruz do Sul: Instituto Souza Cruz, 2002. 325 p.

BAIDER, C.; TABARELLI, M.; MANTOVANI, W. O banco de sementes de um trecho de Floresta Atlântica Montana, São Paulo, Brasil. Revista Brasileira de Biologia, v. 59, p. 319 - 328, 1999.

CALlAWAY, R. M. Positive interactions among plants. Botanical Review, v. 61, p. 306 - 349, 1995.

CALLAWAY, R. M.; WALKER, L. R. Competition and facilitation: a synthetic approach to interactions in plant communities. Ecology, v. 78, p. 1958 - 1965, 1997.

CONNEL, J. H.; SLATYER, R. O. Mechanisms of succession in natural communities and their role in community stability and organization. American Naturalist, v. 111, p. 1119 - 1144, 1977.

DESLOW, J. S. The effect on understory palms and cyclanths on the growth and survival of Inga seedlings. Biotropica, v. 23, p. 225 - 234, 1991.

FOOD AND AGRICULTURE ORGANIZATION (FAO), 2004. State of World's Forests 2004. Disponível em: <http://www.fao.org>. Acesso em: 05/06/2011.

GARWOOD, N. C. Tropical soil seed Banks: a review. In: LECK, M. A.; PARKER, V. T.; SIMPSON, R. L. (ed.). Ecology of soil seed banks. San Diego: Academic Press, 1989. p. 149 - 209.

GÓMEZ-APARICIO, L.; ZAMORA, R.; GOMEZ, M. J.; HODAR, J. A.; CASTRO, J.; BARAZA, E. Applying plant positive interactions to reforestation in Mediterranean mountains: a meta-analysis of the use of shrubs as nurseplants. Ecological Applications, v. 14, p. 1128 - 1138, 2004.

INSTITUTO BRASILEIRO DE GEOGRAFIA E ESTATÍSTICA (IBGE), 2004. Mapa da vegetação do Brasil. Disponível em: <http://www.ibge.gov.br>. Acesso em: 15/11/2011.

KNOB, A. Levantamento fitossociológico da formação Mata do Morro do Coco, Viamão, Rio Grande do Sul. Iheringia, Sér. Bot., v. 23, p. 65 - 108, 1978.

LAMB, D.; GILMOUR, D. Rehabilitation and restoration of degraded forests. Issues in Forest Conservation. IUCN, Gland, Switzerland, 122 p., 2003.

LAURENCE, W. L.; VASCONCELOS, H. L. Consequências ecológicas da fragmentação florestal na Amazônia. Oecologia Brasiliensis, v. 13, n. 3, p. 434 - 451, 2009.

MARCUZZO, B. S.; ARAÚJO, M. M.; SCOTTI, M. Uso de poleiros artificiais na restauração de área degradada no município de Porto Alegre, RS. In: CONGRESSO IBEROAMERICANO E DO CARIBE SOBRE RESTAURAÇÃO ECOLÓGICA, 2009, Curitiba. Anais... Curitiba: SOBRADE, 2009. p. 23 - 30.

MARTINS, S. V.; ALMEIDA, D. P.; FERNANDES, L. V.; RIBEIRO, T. M. Banco de sementes como indicador de restauração de uma área degradada por mineração de caulim em Brás Pires, MG. Revista Árvore, v. 32, n. 6, p. 1081 - 1088, 2008.

McDONNEL, M. J.; STILES, E. W. The structural complexity of old field vegetation and recruitment of bird-dispersed plant species. Vegetatio, v. 56, p. 109 - 116, 1983. 
MELO, V. A. Efeito de poleiros artificiais na dispersão de sementes por aves. Sociedade de Informações Florestais, v. 24, p. 235 - 240, 2000.

MIRITI, M. N. Regeneração florestal em pastagens abandonadas na Amazônia central: competição, predação e dispersão de sementes. In: GASCON, C.; MOUTINHO, P. (eds.). Floresta Amazônica: dinâmica, regeneração e manejo. Manaus: INPA, 1998, p. 179 - 190.

MORELLATO, L. P. C. As estações do ano na floresta. In: H. F. LEITÃO FILHO; MORELLATO (eds.). Ecologia e preservação de uma floresta tropical urbana: Reserva Santa Genebra. Editora da Unicamp, Campinas, 1995. p. 37 - 41.

NIMER, E. Clima. In: IBGE, Geografia do Brasil - Região Sul. Rio de Janeiro: IBGE, 1990. p. 151 - 187.

PAISE, G.; VIEIRA, M. E. Produção de frutos e distribuição espacial de angiospermas com frutos zoocóricos em uma Floresta Ombrófila Mista no Rio Grande do Sul, Brasil. Revista Brasileira de Botânica, v. 28, n. 3, 2005.

RAUN-BLANQUET, J. Fitosociología: bases para el estudio de las comunidades vegetales. 3. ed. Madrid: Blume, 1979. $820 \mathrm{p}$.

REIS, A.; TRES, D. R. Nucleação: integração das comunidades naturais com a paisagem. In: CARGILL. Manejo ambiental de áreas degradadas. Fundação Cargill. 2007. p. 109 - 143.

SANCHOTENE, M. C. Plano Diretor de Arborização de Vias Públicas - PDAU. Secretaria Municipal do Meio Ambiente de Porto Alegre/RS. 2000. 85 p.

SAS INSTITUTE. SAS Online Doc: version 8. Cary: 1999. CD-ROM.

SHIELS, A. B.; WALKER, L. R. Bird perches increase forest seeds on Puerto Rican landslides. Restoration Ecology, v. 11, n. 4, p. 457 - 465, 2003.

SYSTAT. SYSTAT 10 - Statistics I e II. SPSS Inc., Chicago USA. 2000.

SUZUKI, L. G. A. S.; ALVES, M. C. Propriedades químicas de um solo em recuperação tratado com diferentes fontes de matéria orgânica. In: SIMPÓSIO NACIONAL E CONGRESSO LATINOAMERICANO, 6., Curitiba, 2005. Anais... VI Simpósio Nacional e Congresso Latino-Americano: Recuperação de áreas degradadas. 2005. p. 375 - 383.

TRES, D. R.; REIS, A. Técnicas nucleadoras na restauração de floresta ribeirinha em área de Floresta Ombrófila Mista, Sul do Brasil. Revista Biotemas, v. 22, n. 4, p. 59 - 71, 2009.

VAZQUEZ-YANES, C.; OROZCO-SEGOVIA, A. Patterns of seed longevity and germination in the tropical rainforest. Annual Review of Ecology and Systematics, v. 24, n. 1, p. 69 - 87, 1993.

VELOSO, H. P.; GÓES-FILHO, L. Fitogeografia brasileira - Classificação fisionômico-ecológica da vegetação neotropical. Bol. Tec. do Projeto RADAM BRASIL, Série vegetação, v. 1, 1982. p. 1 - 80.

VIEIRA, D. C. M.; GANDOLFI, S. Chuva de sementes e regeneração natural sob três espécies arbóreas em uma Floresta em processo de restauração. Revista Brasileira de Botânica. v. 29, n. 4. 2006.

VOSS, V. Considerações sobre aves e vegetação em ambientes urbanos. In: Encontro Nacional sobre Arborização Urbana, 1985, Porto Alegre. Contribuições técnico-científicas, Secretaria Municipal do Meio Ambiente, 1985, p. 113 - 114.

YARRANTON, G. A.; MORRISON, R. G. Spatial dynamics of a primary succession: nucleation. Journal of Ecology, v. 62, n. 2, p. 417 - 428, 1974.

YOUNG, T. P. Restoration ecology and conservation biology. Biological Conservation, v. 92, p. 73 - 83, 2000. 